\title{
HUBUNGAN KEPUASAN KERJA DENGAN PERILAKU CITIZENSHIP ORGANISASIONAL
}

\author{
Rita \\ Jurusan Manajemen, Fakultas Ekonomi dan Komunikasi, BINUS University \\ Jln. K.H. Syahdan No. 9, Palmerah, Jakarta Barat 11480 \\ rita@binus.ac.id
}

\begin{abstract}
Job satisfaction is a major concern for the organization to achieve effective performance. Each member/employee has citizenship behavior on activities that do and job satisfaction is believed to be related to the behavior of employees. The purpose of this study was to analyze the effect job satisfaction on Organizational Citizenship Behavior (OCB).This study by taking a sample of Non Governmental Organizations (NGO) in Java, which is an organization that is engaged in social and institutional performance is determined by the workers who work to serve the community. Interesting to observe when the OCB research concerning the role of employees in a social institution. So the application of this research carried out by the context in social institutions, especially NGO.The results of multiple regression analysis showed that the positive effect of pay satisfaction on OCB, but the benefits did not significantly affect satisfaction positively on OCB and antecedent factors (pay satisfaction and benefits satisfaction) together - at no significant effect on OCB.
\end{abstract}

Keywords: job satisfaction, human resources, organizational citizenship behavior

\begin{abstract}
ABSTRAK
Kepuasan kerja merupakan perhatian utama organisasi untuk dapat mencapai keefektifan kinerja. Setiap anggota / karyawan memiliki perilaku citizenship pada kegiatan yang dikerjakannya dan kepuasan kerja diyakini berhubungan dengan perilaku para karyawan. Tujuan penelitian ini ialah untuk menganalisa pengaruh kepuasan kerja pada perilaku citizenship organisasional atau Organizational Citizenship Behavior (OCB). Penelitian ini dengan mengambil sampel Lembaga Swadaya Masyarakat (LSM) di Jawa yang merupakan organisasi yang bergerak dalam bidang sosial, dan kinerja lembaga ditentukan oleh para pekerjanya yang bekerja untuk melayani masyarakat. Menarik untuk dicermati bilamana penelitian OCB menyangkut peran karyawan dalam sebuah lembaga sosial. Sehingga aplikasi penelitian ini dilakukan dengan konteks pada lembaga sosial khususnya LSM. Hasil dari analisis regresi berganda menunjukkan bahwa pay satisfaction berpengaruh positif terhadap OCB, namun benefit satisfaction tidak secara signifikan berpengaruh secara positif pada OCB dan faktor anteseden (pay satisfaction dan benefit satisfaction) secara bersama - sama tidak signifikan berpengaruh terhadap OCB.
\end{abstract}

Kata kunci: kepuasan kerja, sumber daya manusia, organizational citizenship behavior 


\section{PENDAHULUAN}

Pemahaman tentang Manajemen Sumberdaya Manusia (SDM) menyebutkan sebagai konsep dan teknik yang dibutuhkan untuk mempengaruhi aspek sumberdaya manusia dalam posisi manajemen, termasuk di dalamnya adalah perekrutan, seleksi, pelatihan, perghargaan (kompensasi) dan penilaian karyawan (Dessler, 1994). Pengembangan strategi yang telah dilakukan secara terus menerus untuk menciptakan manajemen yang efektif telah mendorong perubahan dan pengembangan Sumber Daya Manusia (SDM). Dalam proses perubahan tersebut, perhatian pada kepuasan kerja mendapatkan bagian yang cukup penting. Pentingnya kepuasan kerja tersebut didasari oleh pemikiran bahwa kinerja perusahaan ditentukan oleh kualitas tiap karyawan, seperti yang disebutkan oleh Caudron (2004). Sebagai bagian dari pencapaian strategi perusahaan, maka peran SDM melalui peningkatan semangat karyawan untuk mencapai keunggulan bersaing sangat diperlukan.

Brown dan Peterson (1993) menganalisa dalam kontek akademik, bahwa tidak ada sesuatu yang lebih berharga daripada kepuasan karyawan. Dalam praktik organisasi pentingya perhatian pada karyawan juga tidak hanya ditujukan pada perusahaan saja , namun perlu dilakukan oleh lembaga (agency). Perbedaan organisasi tersebut menurut Denison (1990) disebutkan dimana perusahaan berkaitan dengan pelayanan pada konsumen, sedangkan lembaga berkaitan dengan publik. Lembaga dituntut untuk mengelola operasional berbagai sumberdayanya lebih efektif dan efisien untuk melayani masyarakat.

Menurut beberapa peneliti, kepuasan kerja rupanya diyakini akan berpengaruh terhadap keefektifan kinerja perusahaan melalui kegiatan yang dikerjakannya. Penelitian selanjutnya menemukan bahwa keefektifan kinerja organisasi seringkali dipengaruhi oleh adanya peran karyawan yang melakukan kegiatan lebih (extra-role performance) daripada tugas yang dibebankan padanya (inrole performance). Organ dan Bateman (1983) menyebut kinerja extra-role performance sebagai Organizational Citizenship Behavior (OCB). Penelaahan keterkaitan antara kepuasan kerja dan OCB oleh Lambert (2000) dengan memberikan sebuah argumen dengan sebuah model tentang hubungan langsung antara kepuasan kerja (kepuasan manfaat dan kepuasan pengupahan) dengan Organizational Citizenship Behavior (OCB).

Penelitian tentang OCB telah dilakukan oleh beberapa peneliti, seperti yang dilakukan oleh Moreover et.al (1987) yang menemukan sebuah hubungan antara kepuasan pengupahan dengan extrarole performance. Penelitian yang cukup penting yang mendukung hubungan kepuasan kerja dengan OCB dilakukan oleh Kueh dan Al-Busaidi (2002) serta Garay (2006) yang menemukan bahwa kepuasan kerja positif berpengaruh terhadap OCB.Penelitian-penelitian OCB yang telah dilakukan selama ini berkisar pada hubungan kepuasan kerja karyawan dengan OCB dalam konteks sosial (Garay, 2006), manufaktur (Alotaibi, 2001), lebih lanjut Lambert (2000) mendukung dengan mencermati bahwa dalam penelitian yang belum diperhatikan adalah karakteristik pekerjaan.

Tujuan penelitian ini ialah untuk menganalisa pengaruh kepuasan kerja (kepuasan pengupahan dan manfaat) pada perilaku citizenship organisasional atau Organizational Citizenship Behavior (OCB). Penelitian ini dilakukan dalam konteks sosial yaitu para pekerja Lembaga Swadaya Masyarakat (LSM). LSM merupakan organisasi yang bergerak dalam bidang sosial, dan kinerja lembaga ditentukan oleh para pekerjanya yang bekerja untuk melayani masayarakat. Karakteristik pekerjaan yang berkaitan dengan lembaga sosial belum banyak dilakukan penelitian. Menarik untuk dicermati bilamana penelitian OCB menyangkut peran karyawan dalam sebuah lembaga sosial.

\section{Strategi Sumber Daya Manusia}

Menurut Gibson (1996), perilaku dalam organisasi mempunyai orinetasi terhadap kemanusiaan dan peningkatan kinerja dimana menempatkan aspek manusia dan perilakunya, persepsi, 
kapasitas pembelajaran, perasaan dan sasaran sebagai hal yang penting. Davis (1990) menjelaskan perilaku organisasi secara umum tidak terlepas dari pokok pembentuknya yaitu orang, struktur, teknologi dan lingkungan. Dari keempat unsur pokok tersebut manusialah yang sangat mempengaruhi efektifitas setiap organisasi, sehingga manusia merupakan sumber daya yang penting dalam organisasi. Keberhasilan organisasi salah satunya terletak pada faktor Sumber Daya Manusia (SDM). Keberhasilan organisasi akan diukur oleh kemampuan perusahaan mencapai sasaran yang diharapkan baik dalam pertumbuhan maupun profitabilatas, atau dapat bertahan untuk jangka pendek dan panjang. Hal ini menyebabkan pengelolaan manusia sebagai SDM organisasi yang sentral menjadi suatu permasalahan yang penting dalam manajemen organisasi. Tanpa SDM yang berkualitas, SDM tidak akan bermanfaat secara maksimal (Pradiansyah, 1999). SDM yang berkualitas bukan saja menggambarkan kualitas loyalitas pada organisasi, namun juga memerlukan perhatian organisasi. Untuk itu dibutuhkan komitmen dalam organisasi yang menempatkan SDM sebagai sasaran sentral dalam organisasi. Tanpa komitmen akan sukar mengharapkan partisipasi aktif SDM dalam organisasi.

Pengembangan strategi secara terus menerus untuk menciptakan manajemen yang efektif telah mendorong perubahan dan pengembangan Manajemen Sumber Daya Manusia. Pemahaman tentang Manajemen Sumberdaya Manusia (SDM) menyebutkan sebagai konsep dan teknik yang dibutuhkan untuk mempengaruhi aspek sumberdaya manusia dalam posisi manajemen, termasuk di dalamnya adalah perekrutan, seleksi, pelatihan, perghargaan (kompensasi) dan penilaian karyawan (Dessler, 1994). Pengembangan strategi yang telah dilakukan secara terus menerus untuk menciptakan manajemen yang efektif telah mendorong perubahan dan pengembangan Sumber Daya Manusia (SDM). Dalam proses perubahan tersebut, perhatian pada kepuasan kerja mendapatkan bagian yang cukup penting. Pentingnya kepuasan kerja tersebut didasari oleh pemikiran bahwa kinerja perusahaan ditentukan oleh kualitas tiap karyawan, seperti yang disebutkan oleh Caudron (2004). Dalam kontek akademik, bahwa tidak ada sesuatu yang lebih berharga daripada kepuasan karyawan. Dalam praktik organisasi pentingya perhatian pada karyawan juga tidak hanya ditujukan pada perusahaan saja, namun perlu dilakukan oleh lembaga (agency). Perbedaan organisasi tersebut menurut Denison (1990) disebutkan dimana perusahaan berkaitan dengan pelayanan pada konsumen, sedangkan lembaga berkaitan dengan publik. Lembaga dituntut untuk mengelola operasional berbagai sumberdayanya lebih efektif dan efisien untuk melayani masyarakat.

\section{Kepuasan Kerja}

Kepuasan kerja didefinisikan secara berbeda oleh beberapa peneliti. Kepuasan kerja merupakan sikap akibat proses evaluatif yang membandingkan lingkungan kerja standar dengan lingkungan kerja yang dipersepsikan. Berdasarkan pendapat Milner (1988), kepuasan kerja merupakan sebuah bagian penting faktor outcome organisasi. Kirkman dan Shapiro (2002) menyebutkan dari berbagai penelitian dengan mengindikasikan bahwa pengaruh kepuasan kerja pada outcome organisasi dalam berbagai level seperti sebuah perilaku citizenship (OCB). Kepuasan kerja pada kenyataannya didasarkan sebagai variabel yang utama yang mempengaruhi kinerja OCB yang dipadukan dengan variabel individual lainnya (komitmen, dukungan pemimpin dan keterbukaan).

Dessler (1994) menyebutkan bahwa penghargaan merupakan bagian yang penting bagi kepuasan kerja. Penjelasan lebih jauh tentang penghargaan mendefinisikan compensation (kompensasi) sebagai bentuk financial return, pelayanan dan manfaat yang diterima oleh karyawan sebagai bagian dari ketenagakerjaan. Total kompensasi secara keseluruhan dinamakan reward system untuk menarik dan mempertahankan karyawan yang tidak hanya memiliki pengetahuan dan kemampuan yang dibutuhkan, tetapi juga yang memiliki minat dan kemauan untuk mencapai tujuan organisasi. Berdasarkan pemahaman tersebut dapat diperhatikan tentang dua bentuk aspek yang penting yaitu finansial return (kepuasan pengupahan) dan employee benefits (kepuasan manfaat). 
Tingkat kompensasi yang didapatkan oleh individu akan secara signifikan menentukan status sosial, harga diri serta kemampuan pemenuhan kebutuhan saat ini dan keamanan jangka panjang. Kepuasan pengupahan (pay satisfaction) merupakan salah satu aspek penting dari kompensasi yang diterima individu dari pekerjaan mereka. Sedangkan kepuasan manfaat yang diterima merupakan bagian dari reward system yang mendukung dalam kinerja. Bagi karyawan, manfaat yang diterima dari organisasi merupakan sebuah perghargaan.

\section{Perilaku Citizenship}

Perilaku anggota organisasi yang memberikan kotribusi positif bagi organisasi merupakan sebuah pola yang menerapkan pada penekanan sikap - sikap yang konstruktif dan kooperatif, bukan pola pemberian perintah yang ketat dan bukan pula pemberian reward yang sistematis atas suatu bentuk kontrak kerja. Perilaku ini dalam organisasi merupakan bentuk citizenship. Citizenship merupakan sebuah ide yang menyatukan dimensi praktek dan etika, dimana suatau organisasi akan menerapkan suatu kebijakan yang akan dapat meningkatkan aktivitas organisasi.

Kata citizenship dalam Encyclopedia Britanica (1992) dapat berarti sebuah bentuk kebebasan individu yang bertanggung jawab untuk terlibat aktif dalam suatu sistem baik itu negara, organisasi, masyarakat ataupun bentuk - bentuk lain yang merupakan kesatuan yang terorganisasi dalam suatu sistem tertentu secara lebih mendalam. Perilaku citizenship dalam organisasi berfungsi sebagai pelumas pada mesin sosial, dimana akan mengurangi perpecahan internal dan meningkatkan efisiensi. Perilaku citizenship dalam organisasi yang kemudian dinamakan Organizational Citizenship Behavior (OCB) ini oleh beberapa ahli disebut dengan nama yang berbeda. Hal ini dapat terjadi karena situasinya, namun terdapat kesamaan konseptual yang terletak pada definisi sebagai usaha untuk mengidentifikasi perilaku kerja yang memberikan kontribusi yang positif terhadap efektifitas perusahaan, namun seringkali dipandang tradisional untuk menilai hasil kerja.

Konsep OCB ini meningkatkan individu untuk lebih dapat mengaktualisasikan dirinya secara lebih independen dan fleksibel untuk bekerjasama dengan sebanyak mungkin relasi tanpa adanya sifat pemaksaan dan pembatasan pada hubungan kerja yang mendukung terjadinya peningkatan produktifitas kerja. Bentuk OCB dapat diwujudkan tidak terlepas dari konsep perilaku yang diidentifikasi oleh Organ maupun Podsakoff yang dikutip oleh Niehoff dan Moorman (1993) teraktualisasi dalam bentuk sikap suka tolong menolong, hati - hati dalam bertindak, melaksanakan tugas sebaik mungkin, terlibat aktif dalam upaya pengembangan organisasi.

\section{Penelitian-Penelitian tentang OCB}

Penelitian tentang OCB telah dilakukan oleh beberapa peneliti, seperti yang dilakukan oleh Moreover et.al (1987) yang menemukan sebuah hubungan antara kepuasan pengupahan dengan extrarole performance. Penelitian yang cukup penting yang mendukung hubungan kepuasan kerja dengan OCB dilakukan oleh Kueh dan Al-Busaidi (2002) serta Garay (2006) yang menemukan bahwa kepuasan kerja positif berpengaruh terhadap OCB. Penelitian-penelitian OCB yang telah dilakukan berkisar pada hubungan kepuasan kerja karyawan dengan OCB, seperti yang dikemukakan oleh Alotaibi (2001). Penelitian yang dapat dicermati ialah dalam kontek manufaktur. Kontek penelitian secara spesifik menyangkut beberapa dimensi, misalnya Schnake et.al (1995) meneliti pada perusahaan-perusahaan manufaktur. Pengembangan dalam kontek sosial muncul sebuah wacana yang berusaha menghubungkan partisipasi pekerja dalam OCB. Lebih lanjut Lambert (2000) mendukung dengan mencermati bahwa dalam penelitian yang belum diperhatikan adalah karakteristik pekerjaan. Penelitian yang dilakukan oleh Garay (2006) meneliti kontek sosial namun dengan menekankan pada kontek cross-culture. 
Lebih lanjut Lambert (2000) memberikan sebuah argumen dengan sebuah model tentang hubungan langsung antara kepuasan kerja (kepuasan manfaat dan kepuasan pengupahan) dengan Organizational Citizenship Behavior (OCB). Penelitian lain tentang kepuasan kerja dikemukakan oleh Moreover et.al (1987) yang menyebutkan bahwa kepuasan pengupahan mempunyai hubungan dengan OCB. Van Dyne et. Al, (1994) menyebutkan beberapa faktor anteseden yang berpengaruh terhadap OCB, yaitu faktor personal meliputi kepuasan karyawan dalam kerja, persepsi karyawan terhadap situasi lingkungan kerja, dan faktor posisi yaitu posisi karyawan dalam organisasi. Moorman (1991) menunjukkan perlunya adanya penelitian tentang hubungan anteseden dengan OCB, dimana kepuasaan merupakan bentuk potensial anteseden dalam OCB. Damayanti (2003) meneliti hubungan perceived organizational support (POS) dan OCB. Dalam penelitiannya didapatkan bahwa POS mempengaruhi OCB. Berdasarkan penelitian hasil-hasil tersebut maka dapat dibuat hipotesis yaitu:

Hipotesis 1 : Kepuasan pengupahan pekerja mempunyai pengaruh positif terhadap perilaku citizenship organisasional.

Hipotesis 2 : Kepuasan manfaat yang diterima pekerja mempunyai pengaruh terhadap perilaku citizenship organisasional.

Hipotesis 3 : Kepuasan pengupahan pekerja dan kepuasan manfaat yang diterima pekerja secara bersama mempunyai pengaruh terhadap perilaku citizenship organisasional.

\section{METODE}

Hubungan antara kepuasan kerja (kepuasan pengupahan dan kepuasan manfaat) dan perilaku citizenship organisasional sebagai berikut :

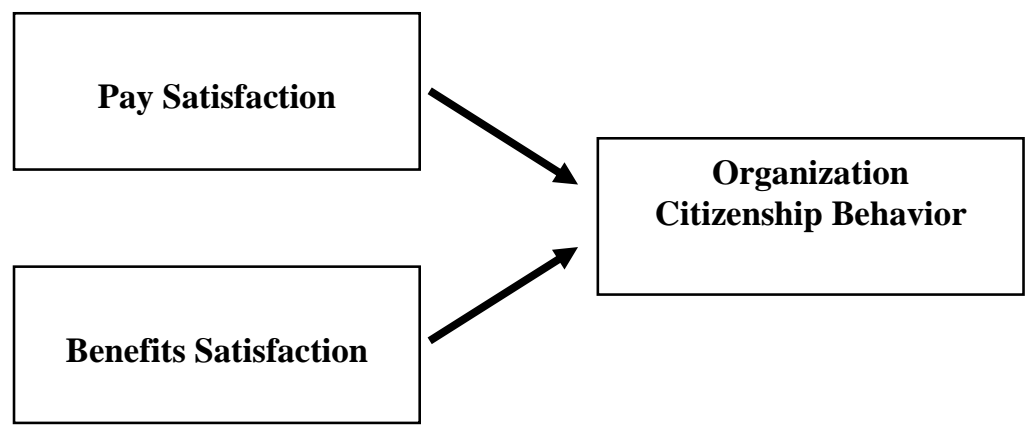

Gambar 1 Model Penelitian

Sumber : Modifikasi dari Lambert (2000) dan Garay (2006)

\section{Desain Penelitian}

Penelitian dilakukan menggunakan metode survei dengan menyebarkan daftar pertanyaan (kuisioner) sebagai instrumen utama dalam pengumpulan data primer sampel populasi. Populasi dalam penelitian ini merupakan organisasi-organisasi yang terlibat dalam kerjasama interagency. Butcher dan Ashton (2004) menyebutkan istilah agen (agency) sebagai organisasi yang bekerja sesuai dengan tujuan. Agency merupakan organisasi nonprofit yang menyediakan jasa pelayanan bagi masyarakat. Populasi dalam penelitian ini adalah para pekerja Lembaga Swadaya Masyarakat (LSM) yang berdomisili atau berkantor di wilayah Jawa. 
Kelompok Organisasi Non Pemerintah (ORNOP) atau Non Governmental Organization (LSM) yang sering disebut sebagai Lembaga Swadaya Masyarakat (LSM) meliputi juga institusiinstitusi swasta serta sukarelawan, baik berasal dari dalam dan luar negeri yang beraktivitas di wilayah Jawa (Jawa Timur, Jawa Tengah, Yogyakarta, Banten dan Jakarta). Teknik purposive sampling dilakukan untuk memilih sampel penelitian berdasarkan kriteria tertentu. Kriteria sampel yaitu pekerja tetap dari organisasi LSM yang berdomisili di Jawa. Sampel dalam penelitian ini adalah organisasiorganisasi. Sampel meliputi Non Governmental Organization (LSM). LSM meliputi sektor swasta sebagai organisasi non profit serta sukarelawan, baik berasal dari lokal, nasional maupun internasional. Responden penelitian merupakan karyawa organisasi LSM.

\section{Metode Pengumpulan Data}

Studi pada penelitian ini menggunakan data primer. Data primer diperoleh melalui penyebaran kuesioner dan langsung pada pekerja LSM. Metode ini dipilih dengan pertimbangan untuk menjangkau area penelitian yang luas dengan biaya yang relatif murah, lebih mampu merahasiakan identitas responden dan memberikan kesempatan kepada responden untuk berpikir sebelum memberikan jawaban pertanyaan. Metode tersebut di atas memiliki kelemahan yaitu rendahnya tingkat respon atau partisipasi responden, tidak ada intervensi pewawancara, format kuesioner harus dibuat dalam bentuk yang menarik dengan pertanyaan yang singkat dan jelas dan hanya membutuhkan waktu \pm 15 menit untuk menjawab, serta diperlukan daftar pengiriman surat yang akurat. Pendistribusian kuesioner juga dilakukan dengan cara mendatangi secara langsung beberapa perusahaan manufaktur yang menjadi obyek penelitian.

\section{Definisi Operasional dan Pengukuran Variabel}

Perilaku citizenship dalam organisasi yang kemudian dinamakan Organizational Citizenship Behavior (OCB) ini oleh beberapa ahli disebut dengan nama yang berbeda. Organ dan Bateman (1983) menyebut kinerja extra-role performance sebagai Organizational Citizenship Behavior (OCB). OCB atau perilaku citizenship organisasional merupakan segala tindakan yang dilakukan oleh karyawan (pekerja) yang memberikan manfaat pada lembaga walapun tanpa mandat (perintah) untuk melakukannya, artinya kegiatan yang dilakukan oleh pekerja tersebut dilakukan secara spontan menurut dorongan dirinya untuk organisasi. Dimensi dalam OCB didasarkan pada penelitian Lambert (2000) dan Garay (2006) yaitu : Helping behavior, Sportmanship, Civic Virtue dan Courtesy. Skala pengukuiran dengan rating scale antara 1 sd 5 , sangat tidak setuju-sangat setuju.

Kepuasan pengupahan (pay satisfaction) merupakan salah satu aspek penting dari kompensasi yang diterima individu dari pekerjaan mereka. Sedangkan kepuasan manfaat yang diterima merupakan bagian dari reward system yang mendukung dalam kinerja. Herman dan Schawb (1985) menyatakan bahwa kepuasan upah dalam organisasi terdiri dari tiga dimensi yang terpisah, yaitu pay level, pay raise, structure administration. Dimensi-dimensi dalam pay satisfaction diukur dengan menggunakan rating scale dari angka $1 \mathrm{sd} 5$, sangat tidak puas-sangat puas.

Penjelasan lebih jauh tentang penghargaan mendefinisikan compensation (kompensasi) sebagai bentuk finansial return, pelayanan dan manfaat yang diterima oleh karyawan sebagai bagian dari ketenagakerjaan. Herman dan schawb (1985) juga menyatakan bahwa kepuasan kerja tidak hanya kepuasan pengupahan tetapi juga meliputi manfaat (benefits) yang diterima pekerja dari organisasi. Mengacu pada sesuatu yang diterima pekerja dalam bentuk pelayanan organisasi padanya. Dimensidimensi dalam benefits satisfaction diukur dengan menggunakan rating scale dari angka 1 sd 5, sangat tidak puas-sangat puas. 


\section{Uji Hipotesis}

Dalam penelitian ini, pengujian hipotesis dilakukan dengan menggunakan analisis regresi berganda (multiple regression analysis). Metode analisis ini digunakan karena dalam pengujian hipotesis terdapat lebih dari satu variabel independen. Perhitungan dilakukan dengan meggunakan bantuan software SPSS 15 for windows (Ghozali, 2005).

\section{HASIL DAN PEMBAHASAN}

\section{Pengumpulan Data}

Penelitian tentang organizational citizenship behavioral dilakukan melalui penyebaran kuisioner, wawancara (interview) maupun elektronik selama kurang lebih 2 bulan. Fokus penelitian ini pada persepsi para karyawan Lembaga Swadaya Masyarakat (LSM) yang merupakan organisasi non pemerintah yang bersifat nonprofit yang berkomitmen dalam kegiatan sosial. Peneliti mendistribusikan sebanyak 153 kuisioner yang dilakukan dengan memberikan kuisioner secara langsung kepada responden yang dituju maupun mengirim kuisioner melalui e-mail. Distribusi kuisioner penelitian dapat dilihat pada Tabel 1:

Tabel 1 Distribusi Kuisioner

\begin{tabular}{lccc}
\hline \multirow{2}{*}{ Keterangan } & \multicolumn{2}{c}{ Distribusi } & Jumlah \\
\cline { 2 - 3 } & Kontak langsung & e-mail & 153 \\
\hline Disebar & 65 & 88 & 85 \\
Kembali & 59 & 26 & 71 \\
Layak Uji & 51 & 20 & $55 \%$ \\
Response Rate & $91 \%$ & $30 \%$ & \\
\hline
\end{tabular}

Sumber: hasil olah data primer

\section{Pengujian Hipotesis dan Pembahasan}

Pengujian hipotesis dalam penelitian ini menggunakan regresi berganda (multiple regression). Pengaruh masing-masing variabel anteseden sesuai uji regresi pada tabel 2 memperlihatkan hasil untuk menentukan didukung atau tidak didukung hipotesis.

Tabel 2 Hasil Analisis Regresi Berganda

\begin{tabular}{|c|c|c|c|c|c|c|}
\hline \multicolumn{2}{|c|}{ Variabel } & $\begin{array}{c}\text { Unstandarized } \\
\text { Coefficients } \\
\text { (B) } \\
\end{array}$ & $\begin{array}{c}\text { Standarized } \\
\text { Coefficients } \\
\text { (Beta) } \\
\end{array}$ & $\mathbf{t}_{\text {hitung }}$ & Sig & Keterangan \\
\hline \multicolumn{2}{|l|}{ Constant } & 41,422 & & 5,687 & 0,000 & \\
\hline \multicolumn{2}{|c|}{$\mathrm{X}_{1}$ (pay stsfac) } & 0,338 & 0,183 & 1,546 & 0,012 & Signifikan \\
\hline \multicolumn{2}{|c|}{$\mathrm{X}_{2}$ (benefit statsf) } & $-0,246$ & $-0,134$ & $-1,127$ & 0,264 & Tidak Signifikan \\
\hline $\mathrm{R}$ & $=0,240$ & & & & & \\
\hline R Square & $=0,058$ & & & & & \\
\hline$F_{\text {hitung }}$ & $=2,087$ & & & & & \\
\hline Sig. F & $=0,132$ & & & & & \\
\hline$\alpha$ & $=0,05$ & & & & & \\
\hline
\end{tabular}

Sumber: Hasil Olah Data Primer 
Tujuan pengujian hipotesis pertama (H1) ini adalah untuk menguji apakah pay satisfaction mempunyai pengaruh positif pada OCB.

$\mathrm{H}_{0}=$ Pay satisfaction tidak mempunyai pengaruh positif dengan OCB.

Ha = Pay satisfaction mempunyai pengaruh positif dengan OCB.

Berdasarkan hasil pada tabel 2, koefisien regresi sebesar 0,183 menerangkan besar kecilnya pengaruh variabel independen terhadap variabel dependen, dan karena koefisien regresi bertanda positif, maka pengaruhnya adalah positif. Pada penelitian ini signifikansi adalah 0,012 lebih keceil dari 0,05 maka dapat disimpulkan bahwa pay satifaction secara signifikan berpengaruh secara positif pada OCB. Oleh karena itu, hipotesis pertama (H1), yaitu pay satisfaction terhadap OCB yang diajukan dalam penelitian ini didukung.

Tujuan pengujian hipotesis kedua (H2) ini adalah untuk menguji apakah benefit satisfaction mempunyai pengaruh positif pada OCB.

$\mathrm{H}_{0}=$ benefit satisfaction tidak mempunyai pengaruh positif dengan OCB.

$\mathrm{Ha}=$ benefit satisfaction mempunyai pengaruh positif dengan OCB.

Koefisien regresi sebesar -0,134 menerangkan besar kecilnya pengaruh variabel independen terhadap variabel dependen, dan karena koefisien regresi bertanda negatif, maka pengaruhnya adalah negatif. Pada penelitian ini signifikansi adalah 0,190>0,05 maka dapat disimpulkan bahwa benefit satisfaction tidak secara signifikan berpengaruh secara positif pada OCB. Oleh karena itu, hipotesis kedua (H2), yaitu benefit satisfaction terhadap OCB yang diajukan dalam penelitian ini tidak didukung.

Alat analisis regresi berganda digunakan untuk menguji signifikansi pengaruh variabelvariabel independen (pay satisfaction dan benefit satisfaction) secara bersama-sama terhadap variabel dependen (organizational citizenship behavior). Hasil uji regresi untuk hubungan variabel dependen dengan independen menunjukkan besarnya koefisien determinasi $\left(\mathrm{R}^{2}\right)=0,058$ yang berarti bahwa variansi $O C B$ yang dapat dijelaskan secara bersama-sama oleh faktor pay satisfaction dan benefit satisfaction adalah 58\%, sedangkan sisanya $42 \%$ dapat diperjelas oleh variabel lain. Uji signifikasi simultan (uji F) menunjukkan nilai $\mathrm{F}$ test yang diperoleh adalah sebesar 2,087 dengan signifikasi 0,132, karena probabilitas 0,132 lebih besar dari 0,05 maka dikatakan bahwa faktor anteseden secara bersama-sama tidak berpengaruh terhadap OCB. Hasil pengujian hipotesis selengkapnya dapat dilihat pada Tabel 3.

Tabel 3 Hasil Hipotesis Berdasarkan Uji Regression Analysis

\begin{tabular}{|c|c|c|}
\hline No & Hipotesis & Hasil \\
\hline H1 & $\begin{array}{l}\text { Pay Satisfaction mempunyai pengaruh positif terhadap } \\
\text { Organizational Citizenship Behavior }\end{array}$ & Didukung \\
\hline $\mathrm{H} 2$ & $\begin{array}{l}\text { Benefit Satisfaction mempunyai pengaruh positif terhadap } \\
\text { Organizational Citizenship Behavior }\end{array}$ & Tidak didukung \\
\hline H3 & $\begin{array}{l}\text { Pay satisfaction dan benefit satisfaction secara bersama sama } \\
\text { berpengaruh pada Organizational Citizenship Behavior }\end{array}$ & Tidak didukung \\
\hline
\end{tabular}

Sumber : Hasil olah data primer

Penelitian hubungan kepuasan kerja dengan perilaku citizenship organisasional dianalisis dengan regresi berganda. Berdasarkan hasil regresi pada pay satisfaction pengaruhnya adalah positif. Pada penelitian ini dapat disimpulkan bahwa pay satifaction secara signifikan berpengaruh secara positif pada OCB. Berdasarkan hasil pada benefit satisfaction menerangkan pengaruhnya adalah 
negatif. Pada penelitian ini dapat disimpulkan bahwa benefit satisfaction tidak secara signifikan berpengaruh secara positif pada OCB. Analisis dengan regresi berganda digunakan untuk menguji signifikansi pengaruh variabel-variabel independen (pay satisfaction dan benefit satisfaction) secara bersama-sama terhadap variabel dependen (organizational citizenship behavior) menunjukkan hasil yang tidak signifikan.

Hasil tersebut mendukung Lambert (2000) yang memberikan sebuah argumen dengan sebuah model tentang hubungan langsung antara kepuasan kerja (kepuasan manfaat dan kepuasan pengupahan) dengan Organizational Citizenship Behavior (OCB), walaupun benefit satisfaction ternyata ditemukan tidak berpengaruh secara sinifikan. Demikian juga seperti Van Dyne et. Al, (1994) yang menyebutkan beberapa faktor anteseden yang berpengaruh terhadap OCB, yaitu faktor personal meliputi kepuasan karyawan dalam kerja, persepsi karyawan terhadap situasi lingkungan kerja, dan faktor posisi yaitu posisi karyawan dalam organisasi. Seperti yang dikemukakan oleh Moorman (1991) yaitu perlunya adanya penelitian tentang hubungan anteseden dengan OCB, dimana kepuasaan merupakan bentuk potensial anteseden dalam OCB.

Penelitian ini menunjukkan berbagai prediktor dalam Organizational Citizenship Behavior (OCB). Kepuasan kerja merupakan bagian dari Percieved Organnization Support (POS) yang diyakini merupakan anteseden bagi OCB. Dalam kepuasan kerja terdapat beberapa prediktor yang oleh para peneliti diyakini memiliki pengaruh pada OCB. OCB penting dalam kehidupan berorganisasi. Konsep OCB ini meningkatkan individu untuk lebih dapat mengaktualisasikan dirinya secara lebih independen dan fleksibel untuk bekerjasama dengan sebanyak mungkin relasi tanpa adanya sifat pemaksaan dan pembatasan pada hubungan kerja yang mendukung terjadinya peningkatan produktifitas kerja. Bentuk OCB dapat diwujudkan dalam bentuk sikap suka tolong menolong, hati-hati dalam bertindak, melaksanakan tugas sebaik mungkin, terlibat aktif dalam upaya pengembangan organisasi.

\section{PENUTUP}

Kepuasan kerja merupakan diyakini berhubungan erat dengan keefektifan kinerja. Setiap karyawan memiliki perilaku citizenship pada kegiatan yang dikerjakannya dan kepuasan kerja berhubungan dengan perilaku para karyawan. Kepuasan kerja merupakan bagian dari Percieved Organnization Support (POS) yang diyakini merupakan anteseden bagi OCB. Dalam kepuasan kerja terdapat beberapa prediktor yang oleh para peneliti diyakini memiliki pengaruh pada OCB. OCB penting dalam kehidupan berorganisasi. Sesuai dengan penelitian-penelitian sebelumnya pada penelitian ini dapat disimpulkan bahwa pay satifaction secara signifikan berpengaruh secara positif pada OCB. Namun demikian ternyata ditemukan benefit satisfaction tidak secara signifikan berpengaruh secara positif pada OCB. Adapun pengujian pay satisfaction dan benefit satisfaction secara bersama-sama terhadap organizational citizenship behavior menunjukkan hasil yang tidak signifikan. Lebih lanjut penelitian ini menunjukkan bahwa hasil yang berbeda dengan teori dan penelitian yang lain karena terkait situasi dan kompleksitas organisasi atau obyek amatan yang berbeda. Dimana perlu dilakukan penelitian yang lain tentang faktor-faktor yang mempengaruhinya. 


\section{DAFTAR PUSTAKA}

Damayanti. (2003). The relationship between percieved organization support and OCB. Master of Management Gadjah Mada University.

Garay, H. V. (2006). Organizational citizenship behavior: A cross cultural study on the impact of job satisfaction. Tesis tidak terpublikasikan, Fakultas Ekonomi, Universitas Gadjah Mada, Yogyakarta.

Ghozali, I. (2005). Aplikasi analisis multivariate dengan program SPSS. Badan Penerbit Universitas Diponegoro.

Lambert, S. J. (2000). Added benefits: The link between work life benefits and organiztional citizents behavior. Academy of Management Journal.

Organ, D.W., \& Konovsky, M. (1989). Cognitive versus affective determinants of organizational citizenship. Journal of applied Psychology. Volume 74: 157-164.

Organ D.W. (1994). Personality satisfaction and organization citizenship Behavior. The Journal of Social Psychology. Volume 13 (3) 339-350. 